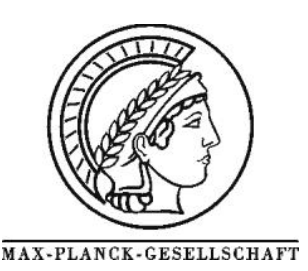

\title{
Combined XPS and TPD study of oxygen-functionalized carbon nanofibers grown on sintered metal fibers
}

\author{
D. Rosenthal ${ }^{1 *}$, M. Ruta ${ }^{2}$, R.Schlögl ${ }^{1}$, L. Kiwi-Minsker ${ }^{2}$ \\ ${ }^{a}$ Fritz-Haber-Institut der Max-Planck-Gesellschaft, Faradayweg 4-6, 14195 Berlin, Germany \\ ${ }^{\mathrm{b}}$ Ecole Polytechnique Fédérale de Lausanne, GGRC-EPFL, Station 6, CH-1015 Lausanne, Switzerland
}

* Corresponding author: e-mail dirkrose@ @ fhi-berlin.mpg.de,

Received 17 July 2009; accepted 20 January 2010. Available online 25 January 2010.

\begin{abstract}
A composite material consisting of carbon nanofibers (CNFs) grown on sintered metal fiber filters was modified by $\mathrm{H}_{2} \mathrm{O}_{2}$ or plasma-generated $\mathrm{O}_{3}$. Coupling temperature programmed desorption (TPD) and X-ray photoelectron spectroscopy (XPS) techniques in the same UHV apparatus allowed the direct correlation of the nature of the created O-functional groups and their evolution as $\mathrm{CO}$ and $\mathrm{CO}_{2}$ upon heating. The two oxidative treatments yielded different distributions of O-containing groups. The relative contribution of oxidized carbon was very low in the C1s region, hence the functional groups were more robustly analyzed through the O1s region. The comparison of the released oxygen by integration of the TPD CO, $\mathrm{CO}_{2}$ and $\mathrm{H}_{2} \mathrm{O}$ spectra with the intensity loss of the XPS O1s spectra showed good agreement. In order to fit the data adequately, the set of O1s spectra was deconvoluted in at least four peaks for the differently activated samples. Finally, it was shown that functional groups formed by $\mathrm{H}_{2} \mathrm{O}_{2}$-treatment (mostly non-phenolic $\mathrm{OH}$ groups) are more thermally stable than those formed by $\mathrm{O}_{3}$-treatment. The latter treatment increases the concentration of carboxylic functionalities, which decompose at temperatures $<800 \mathrm{~K} ; \mathrm{O}_{3}$-activated CNFs should therefore show a more pronounced acidic behavior.
\end{abstract}

\section{Introduction}

Carbon in the form of nanofilaments has been known since it was observed as an undesired product resulting from the thermal decomposition of hydrocarbons over metals [1,2]. More recently, carbon nanofibers (CNFs) have attracted scientific interest in the field of catalysis as they exhibit excellent properties as catalyst supports $[3,4]$. These desirable characteristics include chemical inertness under reaction conditions, good thermal and electrical conductivity, high surface area and meso-porosity. Although, like graphite, CNFs possess an inert, hydrophobic, nature, for many applications it is both desirable and possible to modify their surface thereby enhancing their wettability by polar solvents. From the perspective of supporting metalcontaining species on CNFs, as is the case in their application as catalyst supports, functionalization of the nanofibres is in some cases a prerequisite. Through treatment with strong oxidizing media, oxygenated groups can be introduced onto the surface of CNF [5-7]. The number and type of these oxygen-containing moieties is highly dependent on the method of preparation. A recent survey regarding the analysis of these groups is given by Boehm [8], and includes titration methods, X-ray photoelectron spectroscopy (XPS), temperature programmed desorption (TPD) and infrared (IR) spectroscopy. In the case of TPD two different interpretations of the data are to be found in the literature. Haydar et al. [9] assign different desorption temperatures to the desorption of a single-type of group but from different surface sites (i.e. carboxylic groups within the range 400 to $600 \mathrm{~K})$. Zhou et al. [10] instead assign distinct desorption temperatures to distinct oxygen functional groups (i.e. 550 $\mathrm{K}$ for carboxylic and $670 \mathrm{~K}$ for anhydride groups). For XPS the situation is similar. The most straightforward O1s deconvolution model comprises only two peaks, at around 533 and $531 \mathrm{eV}$ for singly and doubly bond oxygen, respectively [11]. Models based on greater differentiation use up to 5 or more peaks for the O1s deconvolution [10]. Interestingly, only a few studies have been reported where an examination of samples with known oxygen functional groups have been conducted [12-14] . Considering the early studies on polymers by Clark et al. [12,13] it was shown that the binding energy range of $\mathrm{O} 1 \mathrm{~s}$ is about $2 \mathrm{eV}$, however accounting for carbonates and several, only calculated, 
peroxo-species it increases to $\sim 2.5 \mathrm{eV}$. The assignment of groups and the binding energies for these groups differ slightly within their work. For example, when comparing [12] p. 3181 and [13] p. 959f the assignment of groups as a function of increasing binding energy is as follows:

1. Doubly-bonded oxygen in esters, carbonates and acids $(\sim 532.8-532.9 \mathrm{eV})$,

2. Oxygen in isolated carbonyls, ethers and alcohols $(\sim$ $533.6-533.7 \mathrm{eV}$ ),

3. Singly-bonded oxygen in acids and esters $(\sim 534.3$ $\mathrm{eV})$,

4. Singly-bonded oxygen in carbonates $(\sim 535.0-535.2$ $\mathrm{eV})$.

A recent investigation of polymers [14] provides a different picture. First of all the binding energies are in the range of $531.5-533.4 \mathrm{eV}$. If we shift the binding energy region of Clark et al. to map both regions, a carbonylpolymer is in the lowest binding energy $(531.5 \mathrm{eV})$ region similar to Clarks et al. region 1, an ether-polymer in region $2(532.6 \mathrm{eV})$ and alcohol-polymers (phenolic and aliphatic) are in region $3(533.3-533.4 \mathrm{eV})$. We will therefore refer to both studies in our discussion of the XPS data below.

It appears obvious that, at present, TPD and XPS as individual methods are not capable of univocally identifying the different types of functional groups present on functionalized CNFs. A combination of both techniques is however useful as the interpretation of the data must be consistent between both methods.

The aim of this work is the characterization of oxygen-containing groups created on the surface of CNFs grown on inconel sintered metal fiber material $\left(\mathrm{CNF} / \mathrm{SMF}_{\text {Inconel }}\right)$ [15-17] by two different oxidative methods. For this purpose, we have coupled a step-wise TPD with XPS in the same UHV apparatus. The paper is outlined as follows: after the experimental section the results of UHV-TPD and XPS are shown and discussed. Finally the effect of stepwise heating on TPD and XPS results is reported and both methods are correlated.

\section{Experimental}

\subsection{Materials}

Sintered metal fibers Bekipor ST 20AL3 (Bekaert Fiber Technology, Belgium) made of inconel 601 (alloy composition: Ni 58-63\%; Cr 21-25\%; Al 1.4\%) in the form of panels (elementary filament diameter $8 \mu \mathrm{m}$; panel size and thickness $3 \times 3 \mathrm{~cm}^{2}$ and $0.49 \mathrm{~mm}$ respectively, porosity $81 \%$, density $750 \mathrm{~g} / \mathrm{m}^{2}$ ) were used as a support for CNFs. $\mathrm{SMF}_{\text {Inconel }}$ consists of micron-sized metallic filaments which have undergone a sintering process in order to obtain a porous mat which can be used as a filter. High purity gases (>99.995\%) were purchased from Carbagas, Switzerland and were used as received. $\mathrm{H}_{2} \mathrm{O}_{2}$ aqueous solution (Fluka) was used as received. Demineralized, bidistilled, water was used throughout the study.

\subsection{Preparation and surface modification of CNF/SMF Inconel}

Prior to the CNF synthesis, the $\mathrm{SMF}_{\text {Inconel }}$ panels were oxidized in air at $650^{\circ} \mathrm{C}$ for 3 hours. Carbon nanofibers (CNFs) were grown on $\mathrm{SMF}_{\text {Inconel }}$ by decomposition of ethane in the presence of hydrogen. All preparation details and the characterization of the $\mathrm{CNF} / \mathrm{SMF}_{\text {Inconel }}$ have been described elsewhere [17]. After the CNF synthesis, $\mathrm{CNF} / \mathrm{SMF}_{\text {Inconel }}$ was treated in an ultrasonic bath to remove non-anchored carbon $(<0.5 \mathrm{wt}$. \%). During this study, the composite $\mathrm{CNF} / \mathrm{SMF}_{\text {Inconel }}$ supports underwent one of two pre-treatments in order to functionalize the CNF surface. In the first case, the supports were functionalised in a $35 \%$ $\mathrm{H}_{2} \mathrm{O}_{2}$ boiling aqueous solution for 4 hours, and then washed with water until neutral $\mathrm{pH}$ was attained. In the second case, the supports were treated for 30 minutes with plasmagenerated $\mathrm{O}_{3}$ formed in a dielectric barrier discharge plasma reactor [18]. The ozone concentration was monitored with an UV absorption monitor (API-450 NEMA): after 30 minutes the output value was constant at 1100 ppm.

\section{3. $T P D$}

The formed functional groups were subsequently characterized by (step-wise) TPD coupled with XPS in an UHV recipient at the FHI, Berlin. The samples of $\mathrm{CNF} / \mathrm{SMF}_{\text {Inconel }}$ were mounted on a $\mathrm{Pt}$ foil in turn mounted on a sapphire sample-support, and inserted into the UHV recipient (base pressure $<3 \times 10^{-10} \mathrm{mbar}$ ). The recipient contained a manipulator with facilities for sample heating by electron-beam impact and was equipped with a differentially pumped QMS 200 quadrupole mass spectrometer (QMS, Pfeiffer Vacuum). The Pt foil prevented the direct contact of the sample with the electron beam and protected the filament from the desorbing gases from the sample. The temperature was measured by a type-K thermocouple spot welded onto the Pt foil. Temperature programmed desorption was performed by placing the sample $\sim 1 \mathrm{~mm}$ from the entrance aperture (1 $\mathrm{mm}$ in diameter) of the differentially pumped QMS. The QMS signal was found to be linear with the pressure in the chamber from UHV up to the $10^{-6} \mathrm{mbar}$ range. The contact between the sample and the Pt foil was not optimized, hence heating was not perfectly homogeneous thereby generating temperature gradients across the sample. In the high temperature region (glowing sample) the temperature difference between the TPD desorption area and the spot-welded thermocouple could feasibly reach more than $50 \mathrm{~K}$, with the thermocouple at higher temperature. The temperature gradients were less severe in the area of the surface from which TPD was analysed. Table 1 summarizes the characteristics of the samples ana 
Table 1. Samples of CNF/SMF inconel analyzed through the study.

\begin{tabular}{lll}
\hline Sample & Oxidant & Analysis \\
\hline \hline $\mathrm{A} 1$ & - & XPS, TPD \\
$\mathrm{C} 1$ & $\mathrm{H}_{2} \mathrm{O}_{2}$ & TPD \\
$\mathrm{C} 2$ & $\mathrm{H}_{2} \mathrm{O}_{2}$ & Combined XPS-TPD \\
$\mathrm{C} 3$ & $\mathrm{H}_{2} \mathrm{O}_{2}$ & TPD \\
D1 & $\mathrm{O}_{3}$ & TPD \\
D3 & $\mathrm{O}_{3}$ & TPD \\
D4 & $\mathrm{O}_{3}$ & Combined XPS-TPD \\
SMF $_{\text {Inconel }}$ & - & TPD \\
\hline
\end{tabular}

lyzed. Firstly, surveys of TPD at heating rate of $13 \mathrm{~K} / \mathrm{min}$ from samples $\mathrm{C} 1, \mathrm{C} 3\left(\mathrm{H}_{2} \mathrm{O}_{2}\right.$-treated) and D1, D3 (ozonetreated) were carried out in order to estimate the temperatures at which $\mathrm{CO}_{2}$ and $\mathrm{CO}$ evolve. After recording the QMS-spectra over the entire temperature range from room temperature to $1200 \mathrm{~K}$, the desired heating steps were selected. Secondly, step-wise TPD with subsequent XPS measurements were performed on two samples (C2 and D4, Table 1). Blank TPD and XPS measurements were performed on $\mathrm{CNF} / \mathrm{SMF}_{\text {Inconel }}$ without oxygen-functionalities (A1, Table 1) and on the inconel support.

\section{4. $X P S$}

After each heating step, XP spectra were recorded at room temperature, using non-monochromatized $\mathrm{Mg} \mathrm{K \alpha}$ radiation $(1253.6 \mathrm{eV})$ for excitation and a hemispherical analyzer (Phoibos 150, SPECS). The binding energy scale of the system was calibrated using $\mathrm{Au} 4 \mathrm{f}_{7 / 2}=84.0 \mathrm{eV}$ and $\mathrm{Cu} 2 \mathrm{p}_{3 / 2}=932.7 \mathrm{eV}$ from foil samples. The analyzed area of the sample by XPS was approximately $1 \mathrm{~mm}$ in diameter and was within the area analysed by TPD. An overview spectrum (0-1000 eV) and narrow regions corresponding to $\mathrm{C} 1 \mathrm{~s}(270-330 \mathrm{eV})$ and $\mathrm{O} 1 \mathrm{~s}(520-540 \mathrm{eV})$ were recorded, the latter two with longer scanning time. The deconvolution of the main O1s peak was performed by means of CasaXPS software. After subtraction of a Shirley background, the peaks were fitted using a nonlinear, least squares routine with mixed Gauss-Lorentz functions. A minimum set of Gauss-Lorentz functions was chosen in order to obtain a reasonable fit. The deconvolution of the main peak in the $\mathrm{C} 1 \mathrm{~s}$ region is generally more difficult and ambiguous, as the relative contribution to the peaks from oxygenated groups compared to that from the asymmetrically shaped graphitized carbon signal is too small to be isolated directly from the spectra. Instead, C1s difference spectra were obtained by normalizing the intensity of both spectra at the minimum of the intensity between the $\mathrm{C} 1 \mathrm{~s}$ and its $\mathrm{Mg}$ satellites and subsequent subtraction without shifting of the binding energy [19]. The $\mathrm{H}_{2} \mathrm{O}_{2}$ functionalized samples always showed traces of tin oxide (binding energy of $\mathrm{Sn}$ $3 \mathrm{~d}_{5 / 2}$ is $\sim 487 \mathrm{eV}$ and after partial reduction at $1040 \mathrm{~K}, \mathrm{BE}$ $\sim 485 \mathrm{eV}$ ). The accompanying oxygen signal is calculated by the atomic sensitivity factors [20] in the range of $5 \%$ of the entire O1s intensity at RT and is therefore not deemed significant.

\section{Results and Discussion}

Results obtained at high temperatures (> $1040 \mathrm{~K}$ ) were discarded for the correlation of XPS and TPD, due to the fact that part of CNFs burns-off at such temperatures. Most probably, some residual metal oxides present on the surface of the inconel support were reduced by carbon thereby evolving $\mathrm{CO}$.

\subsection{TPD results}

During TPD experiments, hydrogen, water, carbon monoxide and carbon dioxide are the prominent desorbing gases. Since hydrogen does not influence the oxygen functional groups it is disregarded in the analysis throughout this paper. The results of $\mathrm{H}_{2} \mathrm{O}, \mathrm{CO}_{2}$ and $\mathrm{CO}$ desorption experiments on samples $\mathrm{C} 1\left(\mathrm{H}_{2} \mathrm{O}_{2}\right.$-treated) and D3 (ozonetreated) are presented in Figure 1.

Desorption of $\mathrm{CO}_{2}$ and $\mathrm{CO}$ commenced at the same temperature. In comparison to TPD under flowing $\mathrm{He}$ which has been carried out previously [16] the peaks observed in UHV-TPD are broader. This could indicate a nonuniform temperature of the sample. However, the TPD spectra from samples treated in the same way is observed to differ only in intensity, but not in overall shape. The most remarkable differences between the two differently treated samples are related to $\mathrm{H}_{2} \mathrm{O}$ and $\mathrm{CO}_{2}$ desorption. A much greater quantity of $\mathrm{H}_{2} \mathrm{O}$ evolves from the hydrogen peroxide-treated sample up to $900 \mathrm{~K}$ as compared to the $\mathrm{O}_{3^{-}}$ treated sample. The origin of this could be either water trapped in micropores or the formation of water from the interaction of functional groups (e.g. adjacent aliphatic $\mathrm{OH}$ groups). Considering $\mathrm{CO}_{2}$ evolution, this was observed from ozone-treated sample, D3, mainly in the lower temperature range $(<800 \mathrm{~K})$, with a maximum at about $600 \mathrm{~K}$. A broader but less intense $\mathrm{CO}_{2}$ evolution from the $\mathrm{H}_{2} \mathrm{O}_{2}$ treated sample, $\mathrm{C} 1$, is observed at low temperature, but is also observed at higher temperature (up to $1000 \mathrm{~K}$ ). In the literature, the evolution of $\mathrm{CO}_{2}$ at low temperature is usually assigned to the carboxylic functional group, while at 

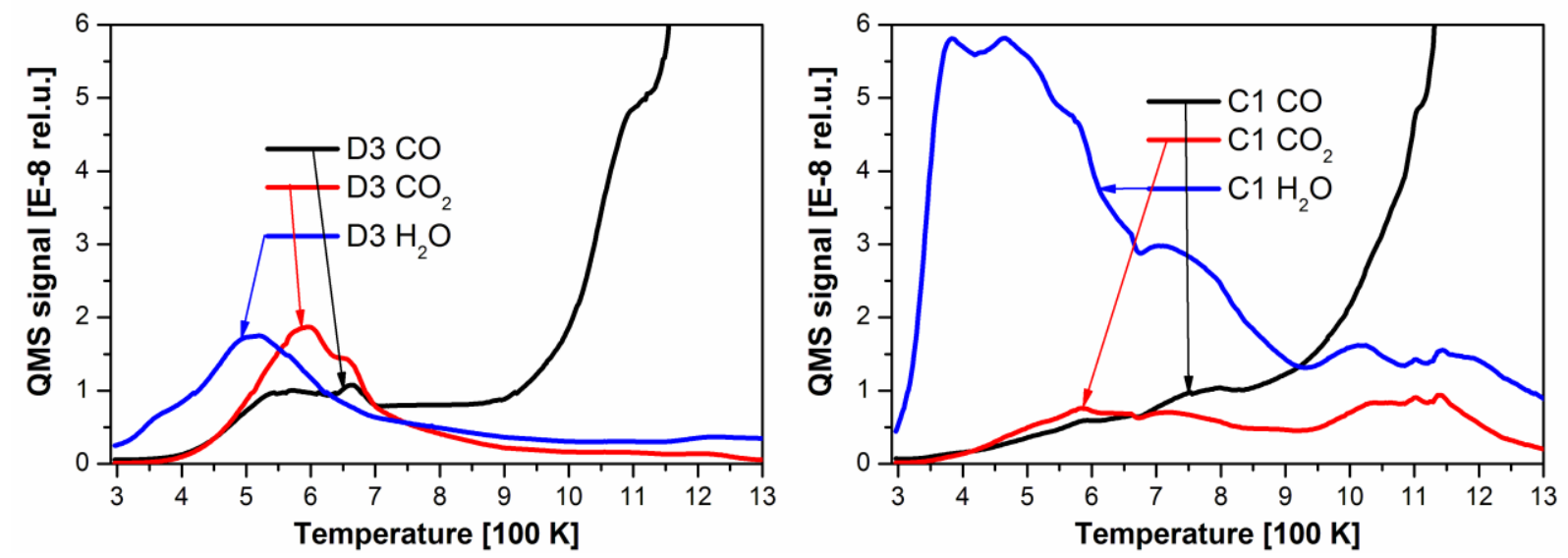

Fig. 1: TPD profiles for the samples D3 (ozone activated, left) and C1 (hydrogen peroxide activated, right).

temperatures higher than $700 \mathrm{~K} \mathrm{CO}_{2}$ is attributed to the decomposition of anhydride and lactone groups [21-23]. CO desorption is dominated by the CNF burn-off at higher temperatures. Additionally however, a broad $\mathrm{CO}$ peak at around $500-600 \mathrm{~K}$ can be observed for the ozone activated sample and two smaller peaks around 600 and $800 \mathrm{~K}$ for the $\mathrm{H}_{2} \mathrm{O}_{2}$ activated sample. $\mathrm{CO}$ formation is usually assigned to the decomposition of phenols, ethers and carbonyls/quinones at high temperature $(>800 \mathrm{~K})[14,16,17]$. However, as referenced in the introduction the interpretation of TPD spectra in the literature is ambiguous. The temperatures of desorption depend on the sample properties, the oxidation conditions, the probability of secondary reactions of the evolved gases (especially in porous carbons [8]) [24], and the manner in which TPD is carried out (e.g. the heating rate).

\subsection{XPS results of the oxidative treatment}

Overview spectra in the range of $0-1000 \mathrm{eV}$ were recorded in order to identify the surface elements present on the samples. For the samples of series $\mathrm{C}$ and D the major constituents identified were carbon and oxygen.

The oxygen to carbon atomic ratios are calculated through the use of the uniform distribution model [20], taking into account the transmission function and the atomic sensitivity factors [20], and are presented in table 2 . This model overestimates the oxygen content if one assumes the more likely case that oxygen is predominately located at the outer surface. For several carbon samples the difference between the uniform distribution and a surface layer model could be up to a factor of 30 [19]. Thus, the very high amount of oxygen in the $\mathrm{H}_{2} \mathrm{O}_{2}$-treated sample $\mathrm{C} 2$ points to more aliphatic carbon on the surface accompanied by a loss of the graphitic character. No oxygen peak was observed in the spectra of sample $\mathrm{A} 1$, demonstrating that the surface oxygen content of untreated $\mathrm{CNF} / \mathrm{SMF}_{\text {Inconel }}$ is
Table 2. Atomic ratios of the used samples after treatment. * Sample $\mathrm{C} 2$ contains also $\mathrm{SnO}_{2}$ and the corresponding atomic ratios are $<1 \%$ oxygen and $<0.5 \%$ tin.

\begin{tabular}{lll}
\hline Sample & Oxygen & Carbon \\
\hline \hline A1 & - & $100 \%$ \\
C2 & $18 \%$ & $80 \%$ \\
D4 & $6.6 \%$ & $93.4 \%$
\end{tabular}

negligible. Figure 2 presents the superposition of the XP spectra in the $\mathrm{C} 1 \mathrm{~s}$ region for non-heated samples $\mathrm{A} 1$ (untreated), $\mathrm{C} 2\left(\mathrm{H}_{2} \mathrm{O}_{2}\right.$-treated), D4 (ozone-treated) and additionally for sample $\mathrm{C} 2$ heated to $1043 \mathrm{~K}$. The difference spectra between oxidized and non-activated samples (D4 and A1) and oxidized $\mathrm{C} 2$ (RT) and heated samples C2 (840K) are shown at the bottom. The observation of the changes in the $\mathrm{C} 1 \mathrm{~s}$ spectra allows us to elucidate the presence of defect sites in the CNF and thus the degree of graphitization $[19,25,26]$. In the case of the ozone-treated sample, D4, the intensity of the peak associated with graphitic carbon $(284.5 \mathrm{eV})$ decreases slightly upon going from the untreated sample to the oxygen functionalized sample.

In contrast, the loss of intensity for the $\mathrm{H}_{2} \mathrm{O}_{2}$-treated sample, $\mathrm{C} 2$, is remarkable: the main signal is much broader and lower than for the untreated sample, A1. It regains some intensity however after heating to $\sim 1000 \mathrm{~K}$. Additionally, the $\pi-\pi^{*}$ loss feature around $291 \mathrm{eV}$ is almost nonexistent after functionalization, regaining some intensity after heating. These results indicate the partial loss of graphitic character, as already alluded above. The contribution of oxidized carbon to the XPS C1s signal can be observed through deconvolution or through analyzing the difference spectra as previously described by Proctor and Sherwood [27]. Both methods have their advantages and drawbacks. Regardless, the analysis is hindered by the stark changes in the carbon signal unrelated to oxygen functionalities, e.g. the loss of graphitic character. One often underestimated drawback of the deconvolution is that the $\mathrm{C} 1 \mathrm{~s}$ intensity of the carbon in oxygen-containing functional groups is very low as compared to the whole $\mathrm{C} 1 \mathrm{~s}$ signal. In 


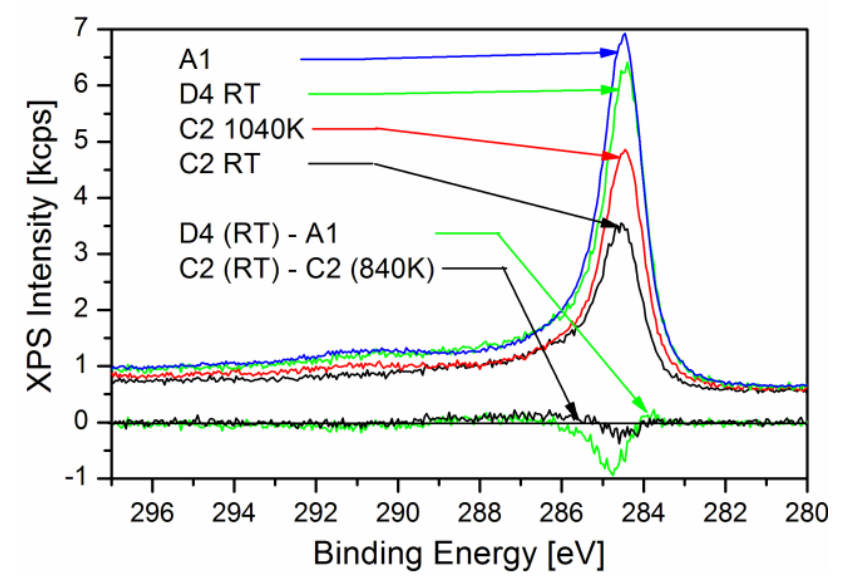

Fig. 2: $\mathrm{C} 1 \mathrm{~s}$ spectra normalized at the minimum of the intensity between the $\mathrm{C} 1 \mathrm{~s}$ and its $\mathrm{Mg}$ satellites of the untreated $\mathrm{CNF} / \mathrm{SNF}_{\text {Inconel }}$ sample A1, the functionalized samples $\mathrm{C} 2\left(\mathrm{H}_{2} \mathrm{O}_{2}\right)$ and $\mathrm{D} 4\left(\mathrm{O}_{3}\right)$ before heating and additionally $\mathrm{C} 2$ after heating to $1040 \mathrm{~K}$ in UHV. In the lower part difference spectra of oxidized/untreated sample (D4 (RT) - A1), and oxidized/heated sample (C2 RT - C2 $840 \mathrm{~K}$ ) are shown.

particular, clean graphitic carbon also shows some intensity in the region of interest $(286-289 \mathrm{eV}[12,28])$, therefore the carbon in oxygen functional groups is often overestimated. It is a good validation to calculate the overall stoichiometric ratio of oxygen to carbon - it should be within the range of 0.5 to 2 (for ethers to carboxylic acids). If the shape of the $\mathrm{C}$ 1s signals vary only slightly the difference method is a good choice. This is the case for the ozone-treated sample (D4). The difference spectrum of untreated and ozonetreated samples is shown at the bottom of Figure 2. By contrast, for the $\mathrm{H}_{2} \mathrm{O}_{2}$-treated sample $\mathrm{C} 2$ it was impossible to calculate meaningful difference spectra with the untreated sample A1. Only calculations of difference spectra from the initial C2 sample with the heated C2 sample up to $840 \mathrm{~K}$ were possible. While the ozone activated D4 sample

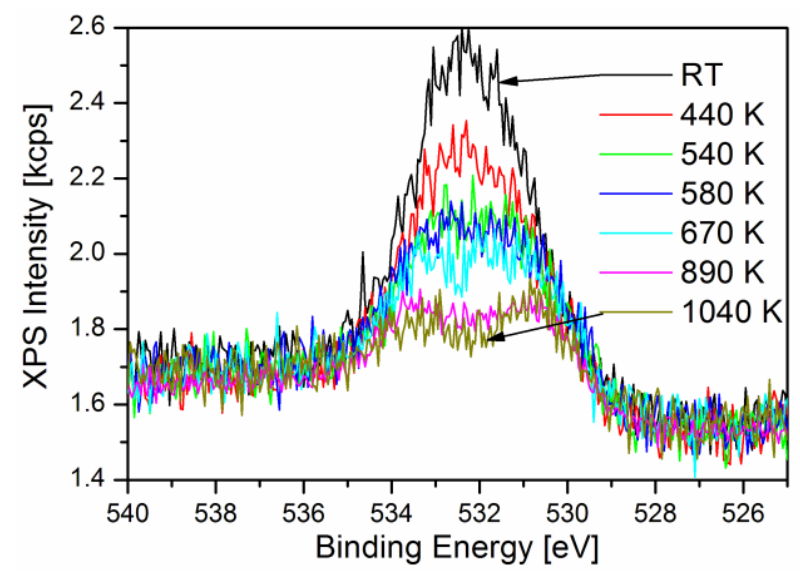

exhibits intensity predominately in the range of $287-289 \mathrm{eV}$ the $\mathrm{H}_{2} \mathrm{O}_{2}$-treated sample $\mathrm{C} 2$ gains some intensity around $286 \mathrm{eV}$. The $\mathrm{C} 1 \mathrm{~s}$ binding energy for $\mathrm{C}$ bound to oxygen follows a simple additive rule, so the binding energy increases with the bond-order of oxygen to carbon. Following this rule we assign the intensity at $286 \mathrm{eV}$ to $\mathrm{C}-\mathrm{OH}$ or to ether groups in the $\mathrm{H}_{2} \mathrm{O}_{2}$-treated sample $\mathrm{C} 2$.

Interestingly, an additional contribution could be observed at $\sim 283.9 \mathrm{eV}$ in the difference spectra of sample D4. This was tentatively assigned to $\mathrm{Ni}_{3} \mathrm{C}$ [29], which is the active phase for the formation of $\mathrm{CNF}$ on $\mathrm{SMF}_{\text {Inconel. }}$ This is supported by the occurrence of a very weak Ni LMM Auger signal.

In the O1s spectra, although the shifts associated with the different functionalities are generally smaller, it is easier to ascertain the overlapping features corresponding to the functional groups because all of the contributions belong to oxygen functional groups. Additionally, the overall intensity is about 2.6 times higher as compared to the accompanying $\mathrm{C} 1 \mathrm{~s}$ signal due to the different atomic sensi tivity factors. The sets of $\mathrm{O} 1 \mathrm{~s}$ spectra resulting from stepwise heating of the same sample are shown in Figure 3. From a mathematical point of view at least four functions are necessary to deconvolute all spectra of one set. For comparison the deconvoluted O1s spectra of samples C2 and D4, before heating, are shown in Figure 4.

The same four peaks (A at $531.3 \mathrm{eV}, \mathbf{B}$ at $532.2 \mathrm{eV}, \mathbf{C}$ at $533.3 \mathrm{eV}, \mathbf{D}$ at $534.8 \mathrm{eV}$, all within a range of $\pm 0.1 \mathrm{eV}$ ) were observed for both samples, while for ozone activated sample D4 an additional peak at lower binding energy $(530.3 \mathrm{eV})$ was needed for the fitting. The assignment of these peaks is not straightforward according to the literature. Peaks A-C may be assigned to The same four peaks (A at $531.3 \mathrm{eV}, \mathbf{B}$ at $532.2 \mathrm{eV}, \mathbf{C}$ at $533.3 \mathrm{eV}, \mathbf{D}$ at 534.8 $\mathrm{eV}$, all within a range of $\pm 0.1 \mathrm{eV}$ ) were observed for both samples, while for ozone activated sample D4 an additional peak at lower binding energy $(530.3 \mathrm{eV})$ was needed for the fitting

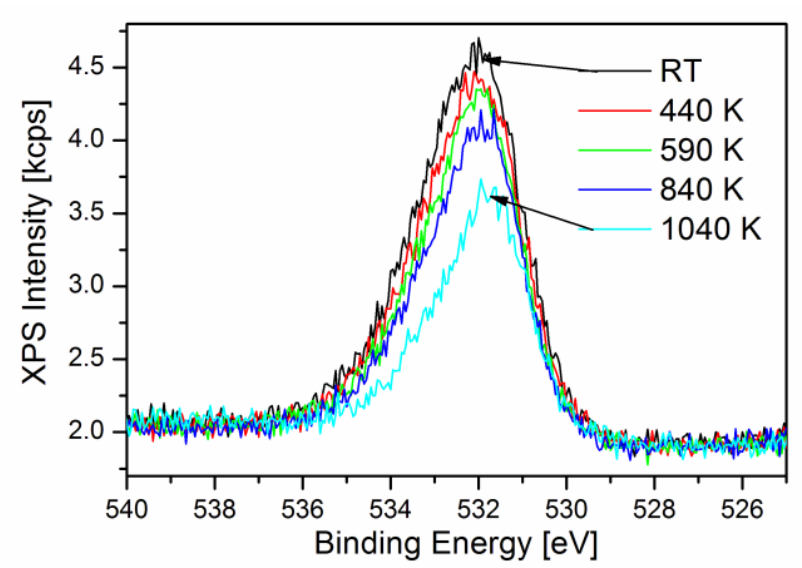

Fig. 3: Development of the XPS O1s spectra of the samples D4 $\left(\mathrm{O}_{3}\right.$, left $)$ and $\mathrm{C} 2\left(\mathrm{H}_{2} \mathrm{O}_{2}\right.$, right $)$ during step-wise heating until $1040 \mathrm{~K}$. The spectra are unrefined, but aligned at the minimum of the intensity between the $\mathrm{O} 1 \mathrm{~s}$ and its $\mathrm{Mg}$ satellites. 


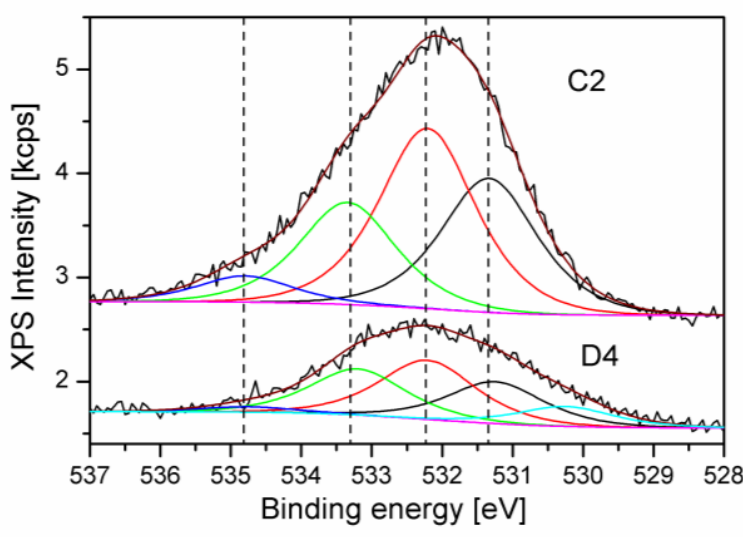

Fig. 4: Superposition of O1s spectra of the samples differently activated before heating in UHV. The $\mathrm{H}_{2} \mathrm{O}_{2}$ activated sample $\mathrm{C} 2$ is offset by $700 \mathrm{kcps}$ for clarity.

The assignment of these peaks is not straightforward according to the literature. Peaks A-C may be assigned to groups 1-3 in the model of Clark et al. [12], but the assignment of peak $\mathrm{D}$ to the occurrence of carbonates is doubtful because of its high temperature stability. Usually these peaks, shifted to higher energy, are explained by differential charging [30]. We tentatively assign the peak at BE $530.3 \mathrm{eV}$ of sample D4 to oxygen atoms bonded to the residual metal present on the sample, which should be insensitive to the heating. Water adsorbed on polycrystalline graphite was found to have a binding energy of around 533 eV [21]. Therefore, we should include adsorbed water in our region $\mathrm{C}$, vide infra. The oxygen/carbon atomic ratios associated with the $\mathrm{C} 1 \mathrm{~s}$ difference spectra are always in the range of $0.5-1.5$, the wide error bar of the difference spectra does not allow further quantification.

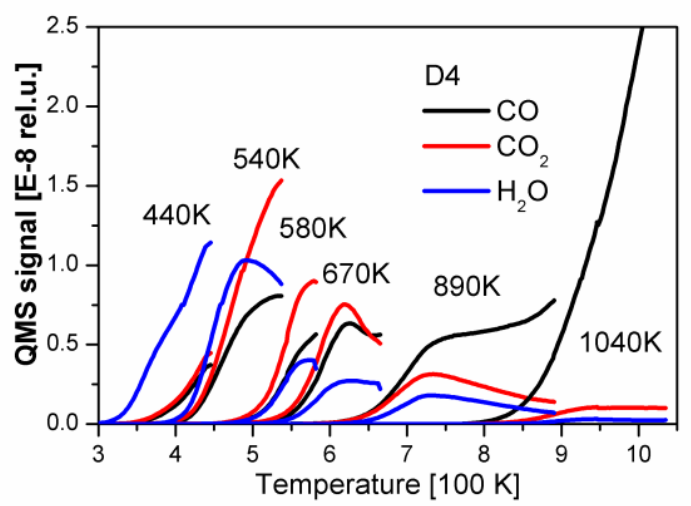

\subsection{Effect of step-wise heating on XPS and TPD results and their correlation}

Following heat treatment, the surface of the CNFs loses a fraction of the functional groups created by the oxidative treatments. From the analysis of the TPD profiles shown in Figure 1 the heating steps for the XPS analysis were chosen in order to analyze the surface composition corresponding to maxima and shoulders in the TPD spectra. The TPD spectra of the step-wise heating of samples C2 and D4 are presented in Figure 5. They show a good agreement with the complete TPD spectra in Figure 1; after addition of all spectra the overall shape is the same. Note that the desorption of water is shown in Figure 5 for the ozone-treated sample D4.

The stepwise heating procedure is justified and does not yield artefacts due to interruption of heating and cooling procedures. Furthermore, in particular for the $\mathrm{H}_{2} \mathrm{O}_{2}$ treated sample the TPD raises doubts that the origin of (most of) the desorbing water signal is adsorbed or trapped water as it would be expected that this would equilibrate over the prolonged heating time. However, we cannot rule out adsorbed water in micro-channels. Another origin could also be the reactive decomposition of oxygen functional groups (for example $\alpha, \beta$ diol groups leaving a ketone group). This is one example where oxygen functional groups are converted into others releasing of an oxygen containing molecule. Amongst others, esters could be converted into ethers.

Fig. 5: Step-wise TPD profiles of $\mathrm{CO}$ (black line) and $\mathrm{CO}_{2}$ (red line) evolution from the samples D4 (ozone activated, left) and C2 (hydrogen peroxide activated, right). For sample D4 also the traces of water without background subtraction are shown. 

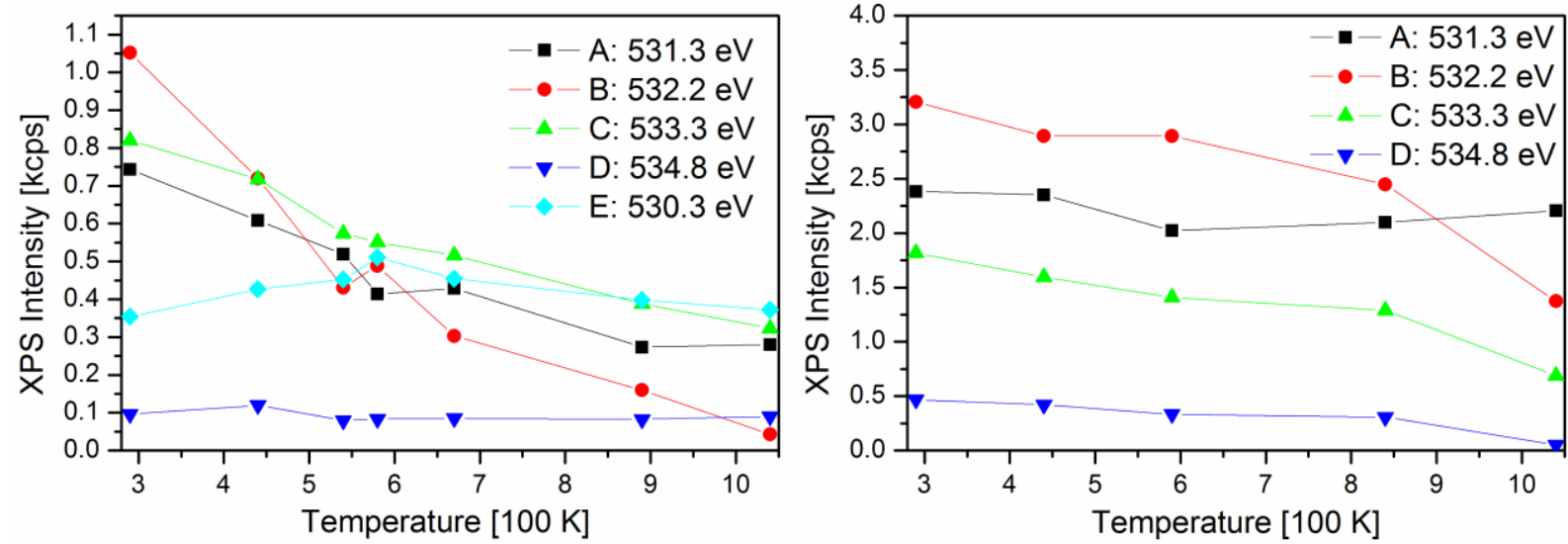

Fig. 6: Development of the XPS O1s decomposition functions in the spectra of the samples $\mathrm{D} 4\left(\mathrm{O}_{3}\right.$, left $)$ and $\mathrm{C} 2\left(\mathrm{H}_{2} \mathrm{O}_{2}\right.$, right $)$ during step-wise heating under UHV.

Following step-wise heating, XPS analysis of the surface was carried out. Although the shape of the spectra changes dramatically for the ozone-treated sample, all spectra could be deconvoluted with the set of functions described in section 3.2, first suggested by Clark et al. $[12,13]$. The development of the intensity of each O1s peak in the deconvoluted $\mathrm{O} 1 \mathrm{~s}$ spectra was calculated and is shown in Figure 6. This allows for the correlation of the $\mathrm{CO}$ and $\mathrm{CO}_{2}$ desorption with the relative decrease in intensity of the peaks in the $\mathrm{O} 1 \mathrm{~s}$ region.

Within the decomposition model of Clark et al. the parallel decreasing signals $\mathbf{A}$ at $531.3 \mathrm{eV}$ and $\mathbf{C}$ at $533.3 \mathrm{eV}$ of the ozone-treated sample D4 should be assigned to carboxylic functional groups. The signal at $\mathbf{B}$ at $532.2 \mathrm{eV}$ must then be assigned to water and CO according to the TPD results. Haydar et al. [9] suggested aldehydes or ketones as the origin of $\mathrm{CO}$ evolution at low temperature. These are isolated carbonyls and hence indeed fall in region 2 in the model of Clark. Water can originate either from adsorbed water or from a chemically bound form of aliphatic alcohol (in accordance with the model of Clark). We are aware that this assignment of water is in contrast to Marchon et al. [21] who indicated a binding energy of approximately $533 \mathrm{eV}$ for water "wetting" graphite, with successively lower binding energies for higher heating temperatures (532.5 eV after flashing to $593 \mathrm{~K}$ ).

With reference to Figure 6 it is seen that significant spectral intensity remains in the high temperature range (900-1000 K) in regions A and C, indicating the presence of very thermally stable functional groups. In contrast, the intensity in region B is much lower. These very stable groups are usually assigned to phenols, ethers and carbonyls directly attached to the $\pi$-system, e.g. in the form of quinones [9]. It should be noted here that these groups are only stable if no additional source of oxygen such as from gasification reactions is present [31]. In our samples such additional oxygen could arise from the oxidized inconel. Significantly, according to the model of Clark [13] one would assign phenols and ethers to region $\mathrm{B}$, which is in contrast to the results of XPS analysis. To the best of our knowledge carbonyls directly attached to the $\pi$-system, e.g. quinones, have not previously been investigated by XPS.

A more recent investigation of polymers by Langley et al. [14] provides differing assignments from those of Clark et al. Specifically, a carbonyl-polymer is located in region $\mathrm{A}$, an ether-polymer in region $\mathrm{B}$ and alcoholpolymers in region $\mathrm{C}$. According to this assignment the highly stable groups observed by XPS would be phenols and carbonyls. Such contrasting conclusions identify the need for further investigation in this area.

Interpretation of the present results is more straightforward in the case of the $\mathrm{H}_{2} \mathrm{O}_{2}$-treated sample. In general, the loss of oxygen functional groups as compared to the remaining groups is considerably lower than for the ozonetreated sample. Here a loss in intensity at low temperature occurs only in regions $\mathbf{B}(532.2 \mathrm{eV})$ and $\mathbf{C}(533.3 \mathrm{eV})$ and leads to a overall shift to lower binding energy. From our employed deconvolution model this excludes the existence of carboxylic groups, as no signal loss is observed in region A. This conclusion is further supported by the absence of a pronounced TPD-CO $\mathrm{C}_{2}$ desorption signal. The small decrease in $\mathrm{O} 1 \mathrm{~s}$ intensity at low temperature is in clear contrast to the large water desorption signal in TPD. Therefore it is evident from the TPD of the $\mathrm{H}_{2} \mathrm{O}_{2}$-treated sample $\mathrm{C} 1$ (fig. 1), which is dominated by water, that the majority of the desorbed water is invisible to the XPS analysis. A possible explanation is (as already discussed in part 3.1) the presence of condensed water in micro channels or the formation of a sp $\mathrm{s}^{3}$ layer with $\mathrm{OH}$ groups mainly beyond of the XPS probing depth. The latter hypothesis is supported by the loss of the graphitic character after $\mathrm{H}_{2} \mathrm{O}_{2}$ treatment, its restoration upon heating to $\sim 1000 \mathrm{~K}$ (Fig 2) and the accompanying loss of water (TPD, Fig. 1). The restoration of the graphitic character could be accomplished through either desorption of aliphatic $\mathrm{OH}$ groups and accompanying formation of a $\mathrm{C}=\mathrm{C}$ bond, or more generally through burningoff of the aliphatic carbon. 

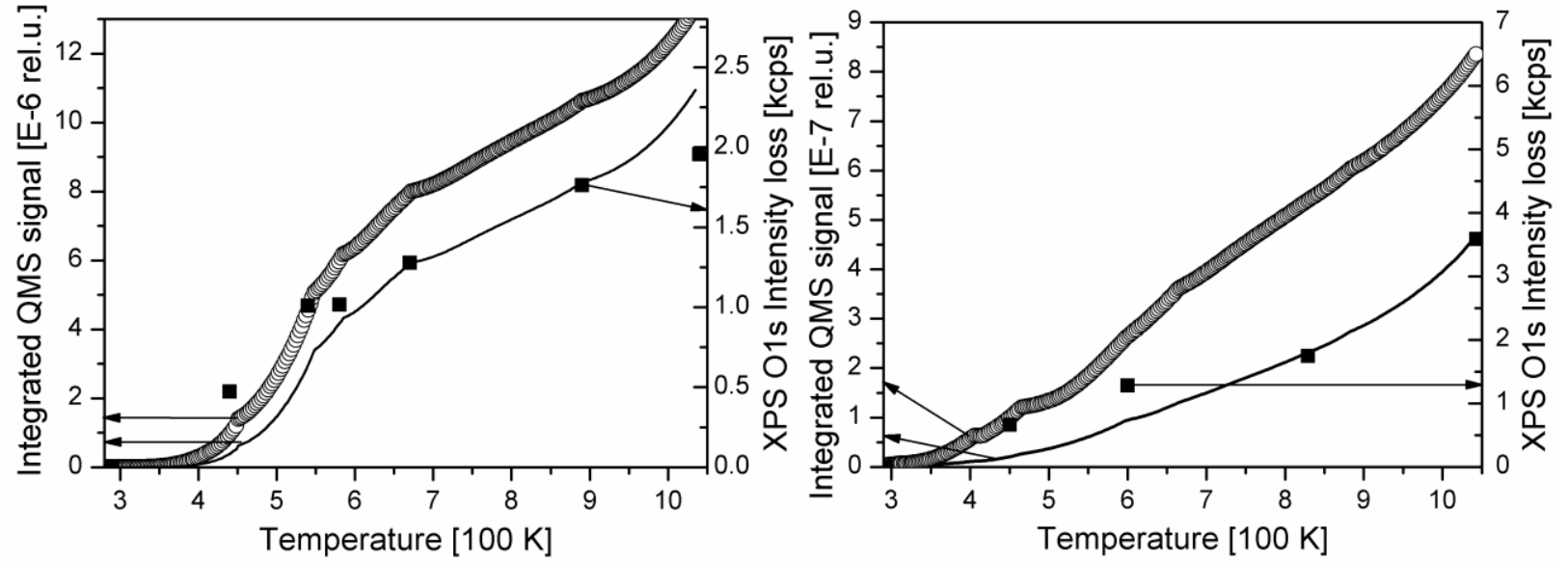

Fig. 7: Two integrated TPD profiles for oxygen in $\mathrm{CO}$ and $\mathrm{CO}_{2}$ (line) and $\mathrm{H}_{2} \mathrm{O}, \mathrm{CO}$ and $\mathrm{CO}_{2}$ together with XPS O1s loss of samples D4 (ozone activated, left) and of sample C2 (hydrogen peroxide activated, right). The XPS and TPD intensities are adjusted in the high temperature range (800-900 K) of the integrated TPD profile without water. Direct quantification and exact adjustment are hampered, due to the different probing depths of the two methods.

The remaining strong $\mathrm{O} 1 \mathrm{~s}$ signal in region $\mathrm{A}$ $(531.3 \mathrm{eV})$ at higher temperature could be explained by the formation of very thermally stable carbonyl or ether groups. Nevertheless, both hypotheses are in contrast to the employed model whereby in region $\mathrm{A}(531.3 \mathrm{eV})$ only $\mathrm{C}=\mathrm{O}$ groups from esters and acids are expected. It is more likely that the assignment of Langley et al. [14] of region A to carbonyls is correct. Further investigations are therefore required in order to improve the XPS deconvolution model.

The integral TPD intensities are compared with the XPS O1s intensity loss in Figure 7. A direct comparison of the amount of oxygen is not possible since the probing depth of both methods is very different and quantification of our TPD data is hampered by the need to estimate the carbon content of the composite samples. Therefore, the curves are adjusted in the high temperature range (800-900 K) of the integrated TPD profile without water, although here the influence of $\mathrm{CO}$ released by carbon burnoff is remarkable. A further caveat is the presence of temperature gradients across the sample and its heterogeneous surface. Despite this, a good correlation is observed between XPS and integral TPD data, particularly for the ozone treated sample D4. Note that adsorbed water contributes to the XPS O1s region, but is ignored in the adjusted TPD integrals. Adsorbed water will contribute in both techniques and therefore may be responsible for the discrepancy at lower temperature. If we add water at low temperature $(<700 \mathrm{~K})$ to the integrated TPD data the correlation becomes even better. The consequence of this is again that the water desorbing at higher temperatures is invisible for XPS, regardless if the origin is water trapped in micro-porosity or chemisorbed in water releasing functional groups.

\section{Conclusions}

Samples of $\mathrm{CNF} / \mathrm{SMF}_{\text {Inconel, }}$, functionalized with Ocontaining groups by two different methods (boiling $\mathrm{H}_{2} \mathrm{O}_{2}$ or plasma-generated $\mathrm{O}_{3}$ ), were successfully characterized by TPD coupled with XPS in the same UHV chamber. This technique was found to be useful in directly linking the release of oxygen containing molecules from the samples at different temperatures with the decomposition of oxygenfunctional groups present on the CNF surface. The TPD analysis provided evidence that the two oxidative treatments yielded different distributions of O-containing groups: $\mathrm{O}_{3}$-functionalized samples contained a relatively higher amount of groups releasing $\mathrm{CO}_{2}$ in the lower temperature range as compared to $\mathrm{H}_{2} \mathrm{O}_{2}$-functionalized samples. The release of significant $\mathrm{H}_{2} \mathrm{O}$ is a good indicator that the initial aim to create a surface wetable by polar solvents has been fulfilled through both oxidation procedures. Stepwise heating with subsequent XPS analysis provided insights into the nature of these $\mathrm{CO}_{2}$ releasing groups. Based on the deconvolution of O1s spectra, it could be shown that they most likely correspond to carboxylic functionalities which tend to decompose at temperatures $<800 \mathrm{~K}$. Following the change in the peak areas after each heating step, it was found that most of the O-groups formed by $\mathrm{H}_{2} \mathrm{O}_{2}$ treatment were more thermally stable than those formed by $\mathrm{O}_{3}$-treatment. The nearly complete loss of intensity in the $\pi-\pi^{*}$ loss feature shows that the $\mathrm{H}_{2} \mathrm{O}_{2}$ treatment heavily disrupts the $\pi$-system of the outer surface of CNFs as probed by XPS (10nm). Since $\mathrm{H}_{2} \mathrm{O}_{2}$ forms $\mathrm{OH}$ radicals it is very likely that a large amount of non-phenolic $\mathrm{OH}$ groups are formed. Temperatures of $1000 \mathrm{~K}$ are necessary to start removing these $\mathrm{OH}$ functional groups again resorting the $\pi$ system. Finally, the overall integral intensities of TPD and XPS during step-wise heating are found to be comparable. The aim of linking TPD desorption signals and XPS signals with specific oxygen-carbon functional groups should 
therefore be achievable with a more sophisticated XPS deconvolution model.

\section{Acknowledgements}

The authors thank Dr. S. Challapalli for the assistance using the DBD-plasma reactor and James McGregor for reading carefully the manuscript. Financial support from the Swiss National Science Foundation and from the EU network of excellence IDECAT is highly appreciated.

[1] Baker RTK. Catalytic growth of carbon filaments. Carbon 1989; 27(3):315-323.

[2] Davis WR, Slawson RJ, Rigby GR. An unusual form of Carbon. Nature 1953; 171(4356):756-756

[3] de Jong KP, Geus JW. Carbon nanofibers: Catalytic synthesis and applications. Cat Rev - Sci Eng 2000; 42(4):481-510.

[4] Serp P, Corrias M, Kalck P. Carbon nanotubes and nanofibers in catalysis. Appl Catal, A 2003; 253:337-358.

[5] Ros TG, van Dillen AJ, Geus JW, Koningsberger DC. Surface oxidation of carbon nanofibres. Chem Eur J 2002; 8(5):1151-1162.

[6] Toebes ML, Prinsloo FF, Bitter JH, van Dillen AJ, de Jong KP. Influence of oxygen-containing surface groups on the activity and selectivity of carbon nanofiber-supported ruthenium catalysts in the hydrogenation of cinnamaldehyde. J Cat 2003; 214(1):78-87.

[7] Toebes ML, van Heeswijk EMP, Bitter JH, van Dillen AJ, de Jong KP. The influence of oxidation on the texture and the number of oxygen-containing surface groups of carbon nanofibers. Carbon 2004; 42(2):307-315.

[8] Boehm HP. Surface oxides on carbon and their analysis: a critical assessment. Carbon 2002; 40(2):145-149.

[9] Haydar S, Moreno-Castilla C, Ferro-Garcia MA, Carrasco-Marin F, Rivera-Utrilla J, Perrard A et al. Regularities in the temperature-programmed desorption spectra of $\mathrm{CO}_{2}$ and $\mathrm{CO}$ from activated carbons. Carbon 2000; 38(9):1297-1308.

[10] Zhou JH, Sui ZJ, Li P, Chen D, Dal YC, Yuan WK. Structural characterization of carbon nanofibers formed from different carbon-containing gases. Carbon 2006; 44(15):3255-3262.

[11] Kundu S, Wang YM, Xia W, Muhler M. Thermal stability and reducibility of oxygen-containing functional groups on multiwalled carbon nanotube surfaces: A quantitative highresolution XPS and TPD/TPR study. J Phys Chem C 2008; 112(43):16869-16878.

[12] Clark DT, Cromarty BJ, Dilks A. Esca applied polymers .24. A theoretical investigation of molecular core binding and relaxation energies in a series of oxygen-containing organicmolecules of interest in the study of surface oxidation of polymers. J Polym Sci Polym Chem Ed 1978; 16(12):3173-3184.

[13] Clark DT, Dilks A. Esca Applied to Polymers .23. Rf glow-discharge modification of polymers in pure oxygen and helium-oxygen mixtures. J Polym Sci Polym Chem Ed 1979; 17(4):957-976.

[14] Langley LA, Villanueva DE, Fairbrother DH. Quantification of surface oxides on carbonaceous materials. Chem Mater 2006; 18(1):169-178.

[15] Tribolet P, Kiwi-Minsker L. Carbon nanofibers grown on metallic filters as novel catalytic materials. Catal Today 2005; 102:15-22.
[16] Ruta M, Semagina N, Kiwi-Minsker L. Monodispersed Pd nanoparticles for acetylene selective hydrogenation: Particle size and support effects. J Phys Chem C 2008; 112(35):1363513641 .

[17] Tribolet P, Kiwi-Minsker L. Palladium on carbon nanofibers grown on metallic filters as novel structured catalyst. Catal Today $2005 ; 105: 337-343$.

[18] Subrahmanyam C, Magureanu A, Renken A, KiwiMinsker L. Catalytic abatement of volatile organic compounds assisted by non-thermal plasma - Part 1. A novel dielectric barrier discharge reactor containing catalytic electrode. Appl Catal , B 2006; 65(1-2):150-156.

[19] Tessonnier JP, Rosenthal D, Hansen TW, Hess C, Schuster ME, Blume R et al. Analysis of the structure and chemical properties of some commercial carbon nanostructures. Carbon 2009; 47(7):1779-1798.

[20] Auger and X-ray photoelectron spectroscopy. Chichester: Wiley, 1990.

[21] Marchon B, Carrazza J, Heinemann H, Somorjai GA. TPD and XPS studies of $\mathrm{O}_{2}, \mathrm{CO}_{2}$, and $\mathrm{H}_{2} \mathrm{O}$ adsorption on clean polycrystalline graphite. Carbon 1988; 26(4):507-514.

[22] Zhuang QL, Kyotani T, Tomita A. The change of TPD pattern of $\mathrm{O}_{2}$-gasified carbon upon air exposure. Carbon 1994; 32(3):539-540

[23] Zielke U, Hüttinger KJ, Hoffman WP. Surface-oxidized carbon fibers .1. Surface structure and chemistry. Carbon 1996; 34(8):983-998

[24] Figueiredo JL, Pereira MFR, Freitas MMA, Orfao JJM. Modification of the surface chemistry of activated carbons. Carbon 1999; 37(9):1379-1389.

[25] Ago H, Kugler T, Cacialli F, Salaneck WR, Shaffer MSP, Windle $\mathrm{AH}$ et al. Work functions and surface functional groups of multiwall carbon nanotubes. J Phys Chem B 1999; 103(38):8116-8121.

[26] Mawhinney DB, Naumenko V, Kuznetsova A, Yates JT, Liu J, Smalley RE. Surface defect site density on single walled carbon nanotubes by titration. Chem Phys Lett 2000; 324(13):213-216.

[27] Proctor A, Sherwood PMA. X-ray photoelectron spectroscopic studies of carbon fibre surfaces. I. carbon fibre spectra and the effects of heat treatment. J Electron Spectrosc Relat Phenom 1982; 27(1):39-56.

[28] Sherwood PMA. Surface analysis of carbon and carbon fibers for composites. J Electron Spectrosc Relat Phenom 1996; 81(3):319-342.

[29] Kroll VCH, Delichure P, Mirodatos C. Methane reforming reaction with carbon dioxide over a $\mathrm{Ni} / \mathrm{SiO}_{2}$ catalyst: The nature of the active phase. Kinet Catal 1996; 37(5):698-705.

[30] Schlögl R. Carbons. In: Ertl G, Knözinger H, Schüth F, Weitkamp J, editors. Handbook of Heterogeneous Catalysis Part 2. Preparation of Solid Catalysts. Wiley-VCH Verlag GmbH \& Co. KGaA, 2008.

[31] Chen SG, Yang RT, Kapteijn F, Moulijn JA. A new surface oxygen complex on carbon - toward a unified mechanism for carbon gasification reactions. Ind Eng Chem Res 1993; 32(11):2835-2840. 